\title{
A breakthrough in probiotics: Clostridium butyricum regulates gut homeostasis and anti-inflammatory response in inflammatory bowel disease
}

\author{
Takanori Kanai $^{1} \cdot$ Yohei Mikami $^{1} \cdot$ Atsushi Hayashi $^{1,2}$
}

Received: 10 April 2015/Accepted: 18 April 2015/Published online: 5 May 2015

(C) Springer Japan 2015

\begin{abstract}
Intestinal immune homeostasis is regulated by gut microbiota, including beneficial and pathogenic microorganisms. Imbalance in gut bacterial constituents provokes host proinflammatory responses causing diseases such as inflammatory bowel disease (IBD). The development of next-generation sequencing technology allows the identification of microbiota alterations in IBD. Several studies have shown reduced diversity in the gut microbiota of patients with IBD. Advances in gnotobiotic technology have made possible analysis of the role of specific bacterial strains in immune cells in the intestine. Using these techniques, we have shown that Clostridium butyricum as a probiotic induces interleukin-10-producing macrophages in inflamed mucosa via the Toll-like receptor $2 /$ myeloid differentiation primary response gene 88 pathway to prevent acute experimental colitis. In this review, we focus on the new approaches for the role of specific bacterial strains in immunological responses, as well as the potential of bacterial therapy for IBD treatments.
\end{abstract}

Keywords Clostridium butyricum - Probiotics · Macrophages · Interleukin-10

Takanori Kanai

takagast@z2.keio.jp

1 Division of Gastroenterology and Hepatology, Department of Internal Medicine, Keio University School of Medicine, Tokyo 160-8582, Japan

2 Research Laboratory, Miyarisan Pharmaceutical Co. Ltd, Tokyo 114-0016, Japan

\section{Introduction}

Crohn's disease and ulcerative colitis, the two major types of inflammatory bowel disease (IBD), are relapsing and remitting conditions characterized by chronic intestinal inflammation caused by aberrant immune responses against the patient's own organs. Genome-wide association studies of IBD have implicated genes connected to the host interaction with microbiota in its pathogenesis, such as NOD2, CARD9, and ATG16L1 [1, 2]. These genetic studies support the idea that perturbations of the host commensal microbiota and host immune system contribute to the pathogenesis of IBD.

In humans, the gastrointestinal tract is home to $10^{14}$ commensal bacteria from many thousands of individual strains [3]. The number of bacterial cells present in the gut ranges from $10^{1}-10^{3}$ per gram of contents in the stomach and duodenum, to $10^{4}-10^{7}$ bacteria per gram in the small intestine, and $10^{11}-10^{12}$ per gram in the colon [4]. In addition, the gut microbial composition differs among gastrointestinal tract sites. Compared with the colon, the small intestine is enriched with sequences of the genus Bacillus of the phylum Firmicutes [5]. In contrast, the phylum Bacteroidetes and the family Lachnospiraceae of the phylum Firmicutes are more prevalent in colonic samples [5]. Methods based on 16S ribosomal RNA gene sequences show that the human gut microbiota is dominated by only two bacterial divisions: the phyla Bacteroidetes and Firmicutes, which constitute more than $90 \%$ of the known phylogenetic categories [6]. The gut microbiota plays a key role in human health and disease.

Many studies have revealed that an imbalance in the bacterial composition (dysbiosis) provokes proinflammatory immune responses and induces inflammatory diseases in the host [7, 8]. Recent progress in gnotobiotic 
technology and metagenomics has made possible analysis of the role of specific bacterial strains in immunological responses. One recent study showed that the 17 strains of clostridia from clusters IV, XIVa, and XVIII derived from the healthy human microbiota induced accumulation of interleukin (IL)-10-producing induced regulatory $\mathrm{T}_{\text {reg }}$ ($\mathrm{T}_{\text {reg }}$ ) cells, which suppressed colitis in a dextran sodium sulfate (DSS)-induced colitis model [9]. Emerging evidence shows that specific commensal bacteria can affect the differentiation of mucosal $\mathrm{T}_{\text {reg }}$ cells under normal conditions [9-12], but it has remained largely unclear which specific bacteria influence mucosa-specific antigenpresenting cell phenotypes such as macrophages and dendritic cells. Unlike these commensal Clostridium strains, the probiotic strain Clostridium butyricum MIYAIRI 588 (CBM588) primarily induced IL-10 production from colonic $\mathrm{F} 4 / 80^{+} \mathrm{CD} 11 \mathrm{~b}^{+}$intestinal macrophages rather than $\mathrm{T}$ cells, and prevented experimental colitis by an IL-10dependent mechanism [13].

Macrophages are essential for maintaining intestinal homeostasis, and are involved in the pathogenesis of IBD. In this review, we discuss the role of $T_{\text {reg }}$ cells and macrophages in gut homeostasis and inflammation, and describe how the gut microbiota, especially clostridia, influences the immune system and colitis.

\section{Gut microbiota and IBD}

IBD is a chronic and relapsing inflammatory disorder caused by a dysregulated immune response to host intestinal microbiota. The target organ of ulcerative colitis is limited to the large intestine, whereas Crohn's disease may involve any part of the gastrointestinal tract, from the mouth to the anus [14]. Accumulation of epidemiological and clinical evidence and recent genetic studies have shown the relationship between IBD and several environmental factors, such as modern lifestyle, diet, antibiotic use, genetic background, and immunological factors [2, 14, 15]. Some of these factors may affect the composition of the gut microbiota $[2,15]$.

The gut microbiota consists of a complex community of microorganisms that live in the gastrointestinal tract. Several techniques have been used to analyze the composition of the gut microbiota, such as culture methods, fluorescence in situ hybridization, and terminal restriction fragment length polymorphism. These studies of the human IBD microbiota have been limited to alterations of the fecal microbiota, thus preventing the possibility that different subpopulations exist within IBD classifications. However, recent advances in next-generation sequencing technology have allowed in-depth characterization of various alterations in the composition of the microbiota in disease states. Most studied have indicated reduced diversity of the gut microbiota in IBD patients, which is due to a reduction in the diversity of Firmicutes. For example, Frank et al. [5] demonstrated that the abundances of bacterial members of the phyla Firmicutes and Bacteroidetes are reduced and those of Actinobacteria and Proteobacteria are increased in IBD. In particular, family Lachnospiraceae, belonging to Clostridium clusters IV and XIVa, is significantly less abundant in IBD patients than in healthy individuals [5]. Sokol et al. $[16,17]$ showed a reduction in representation of the phylum Firmicutes, and particularly Clostridium cluster IV members, Faecalibacterium prausnitzii, in the feces of Crohn's disease patients. However, it remains controversial whether the IBD-associated dysbiosis in the gut microbiota is a cause or a consequence of inflammation, but it is likely to be important in maintaining the diversity of the clostridia to prevent IBD.

No specific pathogenic bacteria associated with IBD have been identified to date. Mycobacterium avium ssp. paratuberculosis has long been suspected as a causative pathogen of Crohn's disease [18]. However, a 2-year clinical trial of an antitubercular drug administered to Crohn's disease patients revealed no efficacy [19]. Other bacterial genera such as Listeria and Mycoplasma have been investigated in relation to Crohn's disease [20, 21]. Adherent-invasive Escherichia coli has been isolated from ileal biopsy samples from patients with Crohn's disease. Pathogenic adherent-invasive Escherichia coli can colonize the ileal mucosa by adhering to intestinal epithelial cells, and is also a true invasive pathogen that is able to invade intestinal epithelial cells [22]. Adherent-invasive Escherichia coli also replicates in macrophages and stimulates production of tumor necrosis factor (TNF)- $\alpha$ by macrophages [22]. In ulcerative colitis patients, Fusobacterium varium attaches to inflamed mucosa and invades ulcerated mucosa [23]. Thus, some specific bacteria might be associated with IBD; however, a role for these bacteria in the pathogenesis of IBD has not been confirmed.

\section{Gut microbiota and experimental models of IBD}

Many different animal models of colitis have been established to investigate the different factors in IBD, by inducing acute or chronic intestinal inflammation. The DSS-induced colitis model exhibits many phenotypic characteristics of human ulcerative colitis. DSS-induced colitis in BALB/c mice was first described by Okayasu et al. [24]. Mice given DSS in their drinking water for several days developed acute inflammation limited to the colon, with weight loss, bloody diarrhea, and histopathological changes. Importantly, acquired immunity is dispensable for this model. Severe combined immunodeficiency mice $[25,26]$ and mice 
deficient in recombination activating gene (RAG)-1 [27, 28], lacking T and B cells, develop colitis after DSS treatment, suggesting innate immune cells are sufficient in the acute phase of DSS-induced colitis, such as macrophages, dendritic cells, neutrophils, and innate lymphoid cells. Although DSS-induced colitis occurs without adaptive immune cells, wild-type mice are more susceptible than RAG-deficient mice to DSS-induced colitis [28]. How DSS initiates colonic inflammation is not fully understood, but some studies have shown that DSS has a direct effect on the inner mucus layer, allowing bacteria to invade the epithelial cells and thus trigger the characteristic inflammatory reaction [29, 30]. In the acute phase, colonic inflammation is characterized by increased levels of $T$ helper $\left(T_{h}\right) 1-T_{h} 17$-mediated inflammatory cytokines such as TNF- $\alpha$, IL-6, and IL-17 [31]. In contrast, a $\mathrm{T}_{\mathrm{h}} 1-\mathrm{T}_{\mathrm{h}} 2$-mediated inflammatory response is found in the chronic phase [31, 32]. IL-17A is an important proinflammatory cytokine that is secreted by $\mathrm{T}_{\mathrm{h}} 17$ cells, and macrophages also produces this cytokine [33]. In a previous study, DSS-induced colitis was ameliorated by administration of IL-17A-neutralizing antibody [34], suggesting that deficiency of IL-17A could relieve the inflammation. It has been shown that the susceptibility of DSS-induced colitis is increased in mice lacking the genes that affect Toll-like receptor (TLR) signaling, such as Tlr2, Tlr4, and Myd88, which encodes myeloid differentiation primary response gene 88 (MyD88), an adaptor molecule of TLRs [35, 36]. These studies have indicated important protective roles of the TLR/MyD88 pathway during the development of colitis.

Patients with long-standing ulcerative colitis have an increased risk of colorectal cancer [37]. Chronic inflammation induced by DSS in combination with azoxymethane (AOM), a classic chemical carcinogen, results in malignancy. This model has also been used to analyze colitisassociated colorectal cancer [38]. IL-1 $\beta$ and IL-18 have key roles in inducing colorectal tumor formation [39-41]. One carcinogenic mechanism of this AOM/DSS model may be that IL-1 $\beta$ induced by neutrophils leads to macrophage production of IL-6, as a tumor promoter [42]. In addition, AOM/DSS $I l 18^{-1-}$ and $I l 18 r 1^{-l-}$ mice are more susceptible to colitis and polyp formation than wild-type mice are [41]. Another study showed that $M y d 88^{-/-}$mice subjected to multiple injections of AOM had reduced colon tumor growth, suggesting that an MyD88-dependent signaling pathway plays a crucial role in carcinogen-induced colonic tumorigenesis [35].

Colitis induced by oxazolone (4-ethoxymethylene-2phenyl-2-oxazolin-5-one) is one of the models suitable for the analysis of the $\mathrm{T}_{\mathrm{h}}$ 2-dependent immune response in progressive intestinal inflammation resembling ulcerative colitis [43, 44]. Intrarectal administration of a single dose of oxazolone leads to acute inflammation through the infiltration of lymphocytes and neutrophils in the distal colon and particular mucosal layers [43]. In addition, repeated intrarectal administration of oxazolone induces chronic inflammation, and IL-13 produced by natural killer (NK) T cells in the lamina propria (LP) is a key pathogenic cytokine in the induction of colitis. Intrarectal administration of oxazolone to CD1-deficient mice and Ja281-deficient mice lacking NK T cells does not result in colitis, and neutralization of IL-13 prevents induction of colitis [44], suggesting that these data have important implications for understanding the treatment of ulcerative colitis.

Another IBD model is 2,4,6-trinitrobenzene sulfonic acid (TNBS)-induced colitis, which mimics patients with Crohn's disease. TNBS-induced colitis is mainly characterized by an increased $\mathrm{T}_{\mathrm{h}} 1$-mediated response, such as IL$12 \mathrm{p} 40$ and interferon (IFN)- $\gamma$, and decreased IL-4 levels, and by infiltration of the LP by T cells and macrophages, with diarrhea, weight loss, and rectal prolapse [31, 45]. Administration of IL-12p40-neutralizing antibody to TNBS-treated mice led to marked improvement in the clinical and histopathological aspects of the disease [45]. LP CD4 ${ }^{+} \mathrm{T}$ cells isolated from anti-IL-12-treated mice failed to induce IFN- $\gamma$ production [45]. IL-12 plays a critical role in promoting $\mathrm{T}_{\mathrm{h}} 1$ responses and cell-mediated immunity. The IL-12 family of cytokines, which includes IL-12, IL-23, IL-27, and IL-35, are key mediators of induction of inflammation. IL-12 consists of a heterodimer of p35 and p40, and IL-12 and IL-23 share a p40 subunit [46]. Several studies have shown that IL-23 is essential for T-cell-mediated colitis and promotes inflammation via IL17 and IL-6 [47]. However, IL-23p19-deficient lacZ knockin mice are more susceptible to the development of experimental T-cell-mediated TNBS colitis than wild-type mice are, suggesting that production of IL-12 is regulated by other IL-12 family members, such as IL-23, during $\mathrm{T}_{\mathrm{h}} 1$ mediated TNBS-induced colitis [48].

Besides these chemically induced models of colitis, there are several spontaneous colitis models. IL-10 and its receptor are reported as susceptibility genes for IBD [1]. IL-10 acts as an immunoregulator to suppress excessive host immune responses against commensal bacteria, and altered function of IL-10 can lead to development of autoimmune diseases. Mice deficient in IL-10 develop spontaneous colitis [49]. However, IL-10 null mice under germ-free conditions do not develop colitis [50], indicating the significance of microbes in this model. Loss of T-bet and RAG genes also induces spontaneous colitis [7]. Wildtype mice co-housed with T-bet and Ragl double knockout mice (TRUC mice) also develop colitis. This suggests that the alteration of microbiota in TRUC mice can cause transmissible colitis.

The transfer colitis model was first reported in 1993. $\mathrm{CD} 4{ }^{+} \mathrm{CD} 45 \mathrm{RB}^{\text {high }} \mathrm{T}$ cells isolated from spleens of donor mice transferred to immunodeficient recipient mice 
(Rag $2^{-l-}$ or severe combined immunodeficiency mice) caused aggressive inflammation in the colon and wasting disease $[51,52]$. In contrast, reconstitution of $\mathrm{Rag}^{-/-}$ mice with $\mathrm{CD}^{+}{ }^{+} \mathrm{CD} 45 \mathrm{RB}^{\text {high }}$ and $\mathrm{CD} 4{ }^{+} \mathrm{CD} 45 \mathrm{RB}^{\text {low }} \mathrm{T}$ cells did not result in development of wasting disease or colitis [53]. Furthermore, $\operatorname{Rag} 2^{-/-}$mice with adoptive transfer of $\mathrm{CD}^{+}{ }^{+} \mathrm{CD} 45 \mathrm{RB}^{\text {low }} \mathrm{T}$ cells from diseased IL-10 knockout mice developed colitis [54], suggesting that IL10 from $C D 45 R^{\text {low }}$ T cells is required for the prevention of colitogenic cells [55]. $\mathrm{T}_{\mathrm{h}}$ cell subsets are supposed to contribute to the pathogenesis of this model, such as $T_{h} 1$, $T_{h} 17$, and $T_{\text {reg }}$ cells. $T_{h} 1$ cells have long been thought to be necessary for pathogenesis of colitis. Naïve $\mathrm{T}$ cells deficient in T-bet [56] or signal transducer and activator of transcription 4 [57], key $\mathrm{T}_{\mathrm{h}} 1$-associated molecules, fail to induce colitis after transfer into immunodeficient mice. However, T-cell-induced IFN- $\gamma$ is dispensable for this model [57]. $T_{h} 17$ is important in the pathogenesis of colitis in mice, but its role is still controversial. O'Connor et al. [58] demonstrated that $\mathrm{Ragl}^{-/-}$mice into which $1117 \mathrm{a}^{-/-}$ $\mathrm{CD} 4{ }^{+} \mathrm{CD} 45 \mathrm{RB}^{\text {high }} \mathrm{T}$ cells were transferred developed severer colitis and wasting diseases, with significantly increased colon IFN- $\gamma$ production, and concluded that IL17A blocks differentiation of $\mathrm{T}_{\mathrm{h}} 1$ cells via IL-17 receptor $\alpha$ on $\mathrm{CD}^{+} \mathrm{T}$ cells. Adoptive transfer of naïve $\mathrm{T}$ cells from $1117 a^{-1-}$, $I l 17 f^{-1-}$, or $1122^{-1-}$ mice into $\mathrm{Ragl}^{-1-}$ mice caused severe colitis that was indistinguishable from that caused by wild-type cells [59]. In contrast, naïve $T$ cells deficient in the transcription factor retinoic acid receptor related orphan receptor (ROR) $\gamma$ [59] or signal transducer and activator of transcription 3 [60], which regulate $T_{h} 17$ differentiation, fail to increase mucosal IL-17 cytokine levels and do not induce colitis when they are transferred into Ragl $^{-1-}$ mice. The role of the $\mathrm{T}_{\mathrm{h}} 17 / \mathrm{T}_{\mathrm{h}} 1$ subsets in this experimental colitis is controversial. To assess this matter, we co-transferred colitogenic $\mathrm{CD} 4^{+} \mathrm{T}$ cells isolated from $\mathrm{CD} 4^{+} \mathrm{CD} 45 \mathrm{RB}^{\text {high }} \mathrm{T}$ cells from Rag2 $2^{-/-}$mice and $I l 10^{-1-}$ mice into Rag $2^{-1-}$ mice [61]. Mice that underwent cotransfer developed colitis to an extent similar to that in mice into which one type of cell was transferred [61]. The proportions of IFN- $\gamma$ - and IL-17A-expressing $\mathrm{CD} 4^{+} \mathrm{T}$ cells in mice that underwent co-transfer were significantly decreased compared with those in mice with single transfer, suggesting colitogenic $T_{h} 1$ and $T_{h} 17$ cells are in competition in this form of colitis [61]. We investigated the plasticity between $T_{h} 1$ and $T_{h} 17$ cells in vivo. When $\mathrm{CD} 4{ }^{+} \mathrm{CD} 45 \mathrm{RB}^{\text {high }} \mathrm{T}$ cells derived from ROR $\gamma \mathrm{t}$ reporter mice were transferred into Rag $2^{-1-}$ mice, the latter mice developed $\mathrm{T}_{\mathrm{h}}$ 1-dependent colitis [62]. ROR $\gamma \mathrm{t}^{+}$cells are induced to express T-bet and differentiate to IL-17 $\mathrm{A}^{-}$IFN$\gamma^{+}$alternative $T_{h} 1$ cells via IL-17A ${ }^{+}$IFN- $\gamma^{+} T_{h} 17 / T_{h} 1$ cells and IL-17A ${ }^{-}$IFN- $\gamma^{+}$ROR $\gamma t^{+}{ } \mathrm{T}_{\mathrm{h}} 1$-like cells [62]. In addition, we recently indicated that both alternative $T_{h} 1$ cells and $\mathrm{T}_{\mathrm{h}} 1$-like cells have the potential to be colitogenic in an adaptive transfer model [63]. These data suggest a critical role for the plasticity of these $\mathrm{T}$ cell types in the development of experimental colitis.

\section{Regulation of immune system by the intestinal microbiota}

Recent advances in metagenomics, proteomics and gnotobiotic technology have made possible analysis of the role of specific bacterial strains in immunological responses $[64,65]$. With use of these approaches, a recent study showed that commensal bacteria promote immune responses and specific $T$ cell subsets, such as $T_{h} 17$ cells and $\mathrm{T}_{\text {reg }}$ cells (Table 1 ).

Segmented filamentous bacteria (SFB) are Gram-positive anaerobic bacteria and are members of the phylum Firmicutes and are similar to clostridia [66]. SFB associate with the intestinal epithelium and enhance $\operatorname{IgA}$ production by $B$ cells, serum amyloid A dependent $T_{h} 17$ cell differentiation in the LP of the terminal ileum, and production of proinflammatory cytokines, such as IL-17 and IL-22 [67, 68]. Mice colonized with SFB show amelioration of infection with Citrobacter rodentium, but SFB can also induce colitis in genetically susceptible animals, suggesting immune activation by SFB can control infection but they can cause inflammation [69]. Specific-pathogen-free C57BL/6 mice from Taconic Biosciences (formerly Taconic Farms) have increased levels of IL-17-producing T cells in the LP of the small intestine compared with mice from the Jackson Laboratory [67]. Study of germ-free mice colonized with cecal contents from Taconic Biosciences B6 or Jackson Laboratory B6 mice revealed that mice colonized with feces of Taconic Biosciences B6 mice led to recovery of normal proportions of $L P \mathrm{~T}_{\mathrm{h}} 17$ cells, but that this did not occur in mice colonized with feces from Jackson laboratory B6 mice [67]. SFB are important for induction of $T_{h} 17$ cells and promotion of $T_{h} 17$-mediated autoimmune disease in animal models; however, it still unclear how the bacteria modulate $\mathrm{T}_{\mathrm{h}} 17$ cell homeostasis. A recent study reported that presentation of SFB antigens on MHC II in the small intestinal LP CD11 ${ }^{+}$dendritic cells led to the induction of SFB-specific intestinal $T_{h} 17$ cells [70, 71]. Goto et al. [71] demonstrated SFB-mediated $\mathrm{T}_{\mathrm{h}} 17$ cell induction in the gut involves SFB-derived antigens and generation of SFB-specific $\mathrm{T}_{\mathrm{h}} 17$ cells. SFB-induced intestinal $\mathrm{T}_{\mathrm{h}} 17$ cells recognize $\mathrm{SFB}$ antigen presentation by MHC II in the periphery. In contrast, SFBindependent $T_{h} 17$ cells are generated even in the absence of MHC II. Thus, expression of MHC II on CD11c cells is necessary and sufficient for SFB-induced $\mathrm{T}_{\mathrm{h}} 17$ cell differentiation. Yang et al. [70] also demonstrated that the 
Table 1 Gut microbes promote immune response and specific T cell subsets

\begin{tabular}{|c|c|c|c|}
\hline Microbes & Cell type & Mechanisms and functions & References \\
\hline SFB & $\begin{array}{l}\mathrm{T}_{\mathrm{h}} 17 \text { cells }(\mathrm{IL}- \\
17, \mathrm{IL}-22)\end{array}$ & $\begin{array}{l}\text { SAA-dependent } T_{h} 17 \text { cell differentiation in the small intestine } \\
\text { SFB-induced } T_{h} 17 \text { cells recognize SFB antigens produced by dendritic } \\
\text { cells }\end{array}$ & {$[67,68]$} \\
\hline Clostridium clusters XIVa and IV & $\begin{array}{l}\text { Foxp3 } 3^{+} \mathrm{T}_{\text {reg }} \\
\text { cells (IL-10) }\end{array}$ & $\begin{array}{l}\text { Clostridium induces TGF- } \beta \text { in intestinal epithelial cells to promote IL- } \\
10 \text {-producing } \mathrm{T}_{\text {reg }} \text { cells }\end{array}$ & {$[9,10]$} \\
\hline Chloroform-resistant bacteria & $\mathrm{T}_{\text {reg }}$ cells $(\mathrm{IL}-10)$ & $\begin{array}{l}\text { Commensal-microbe-derived butyrate induces colonic } \mathrm{T}_{\text {reg }} \text { cells in an } \\
\text { FFAR2 (GPR43)-dependent manner }\end{array}$ & {$[93]$} \\
\hline $\begin{array}{l}\text { Faecalibacterium prausnitzii } \\
\text { (Clostridium cluster IV) }\end{array}$ & $\mathrm{T}_{\text {reg }}$ cells? & $\begin{array}{l}\text { Metabolite (short-chain fatty acid? or active molecule?) increases } \\
\text { secretion of IL-10 }\end{array}$ & [17] \\
\hline Bacteroides fragilis & $\begin{array}{l}\text { Foxp } 3^{+} \mathrm{T}_{\text {reg }} \\
\text { cells (IL-10) }\end{array}$ & PSA interacts with TLR2-expressing $\mathrm{T}$ cells to induce colonic $\mathrm{T}_{\text {reg }}$ cells & $\begin{array}{l}{[11,12,} \\
90]\end{array}$ \\
\hline
\end{tabular}

FFAR2 free fatty acid receptor 2, Foxp3 forkhead box p3, GPR43 G-protein-coupled receptor 43, PSA polysaccharide A, SAA serum amyloid A, $S F B$ segmented filamentous bacteria, $T G F$ transforming growth factor, $T_{h} 17$ cells $\mathrm{T}$ helper 17 cells, $T L R$ Toll-like receptor, $T_{\text {reg }}$ cells regulatory T cells

T-cell antigen receptor repertoire of intestinal $\mathrm{T}_{\mathrm{h}} 17$ cells is restricted to SFB antigens, which implies that microbial antigens could decide the differentiation of antigen-specific $\mathrm{T}$ cells.

IL-22 is another important $T_{h} 17$ cytokine also produced by innate lymphoid cells [72]. A human NK cell subset provides an innate source of IL-22 for mucosal immunity [73-77]. IL-22 is a member of the IL-10 cytokine family. IL-22 binds to a heterodimeric receptor composed of two subunits, IL-10R2 and IL-22R1. IL-10R2 is ubiquitously expressed, but IL-22R1 is exclusively expressed on nonhematopoietic cells [78]. IL-22 induces various genes of antimicrobial peptides, mucin production, and cellular differentiation, and maintains mucosal barrier function [79-81]. IL-22 prevents host infection with the Gramnegative enteric bacterium Citobacter rodentium [82-84], or peripheral dissemination of commensal bacteria [85]. Although IL-22 promotes inflammation in some models, such as Toxoplasma gondii, IL-22 is one of the key cytokines to maintain the balance between gut and commensal bacteria.

Intestinal $\operatorname{IgA}$ is involved in limiting the invasion of pathogenic bacteria into host tissue and regulating the composition and function of the commensal microbiota. In animals deficient in activation-induced cytosine deaminase, the absence of hypermutated $\operatorname{IgA}$ shows that these mice display lymphoid hyperplasia of the gut and an altered microbiota, and therefore IgA is a key factor for regulation of bacterial composition and represents the immune system involved in maintenance of homeostasis [86]. Impaired IgA selection results in uncontrolled $\mathrm{T}$ cell proliferation that severely affects the balance of microbial composition and disease in the intestine [86]. IgA responses are involved in maintaining host-bacterium mutualism by limiting innate immune responses to a specific gut microbiota [87]. A recent study by Kawamoto et al. [88] demonstrated an important role of $\mathrm{T}_{\text {reg }}$ cells in promoting the diversity of the microbiota through regulation of $\operatorname{IgA}$ selection and in facilitating bacterial species responsible for gut homeostasis. To assess which $\mathrm{CD}^{+}{ }^{+} \mathrm{T}$ cell subsets contribute to the diversity and composition of the gut microbiota, naïve $\mathrm{CD} 4^{+} \mathrm{T}$ cells or forkhead box $\mathrm{p} 3$ (Foxp3) ${ }^{+} \mathrm{T}$ cells were transferred into mice lacking $\mathrm{T}$ cells $\left(\mathrm{Cd} 3 e^{-l-}\right)$. The transfer of naïve $\mathrm{CD}^{+}{ }^{+} \mathrm{T}$ cells alone decreased microbiota complexity even in the absence of overt inflammation. By contrast, co-transfer of naïve CD4 ${ }^{+} \mathrm{T}$ cells and Foxp $3^{+} \mathrm{T}$ cells, or transfer of Foxp $3^{+} \mathrm{T}$ cells alone increased bacterial diversity and modified the composition of the microbiota to the degree of the wild-type mice [88]. In addition, Foxp $^{+} \mathrm{T}$ cells can promote the diversification of Firmicutes, including Clostridium clusters IV and XIVa, which are inducers of $\mathrm{T}_{\text {reg }}$ cells $[9,10,88]$. These results strongly suggest that clostridia can not only induce Foxp3 expression, but Foxp $3^{+} \mathrm{T}$ cells can induce the expansion of these bacteria, which are required for the establishment of microbial communities in the gut under normal and inflammatory conditions. Kawamoto et al. [88] also demonstrated a mutual relationship between the adaptive immune response and the gut microbiota. Colonization of germ-free mice with the feces from $\mathrm{Cd} 3 e^{-/-}$mice into which with naïve $\mathrm{CD} 4^{+} \mathrm{T}$ cells or Foxp3 ${ }^{+} \mathrm{T}$ cells were transferred showed that Foxp $3^{+} \mathrm{T}$ cells induce $\mathrm{T}$ follicular helper cells and generate more IgA-producing cells and $\mathrm{T}_{\text {reg }}$ cells as compared with naïve $\mathrm{CD}^{+} \mathrm{T}$ cells [88]. These findings may have important consequences in disease related to dysbiosis of IBD.

Bacteroides fragilis is a Gram-negative bacterium and belongs to the phylum Bacteroidetes. Polysaccharide A (PSA) from Bacteroides fragilis was originally identified to mediate establishment of a proper $T_{h} 1 / T_{h} 2$ balance for the host [89]. Further study showed that colonization of germfree mice by Bacteroides fragilis or treatment with purified 


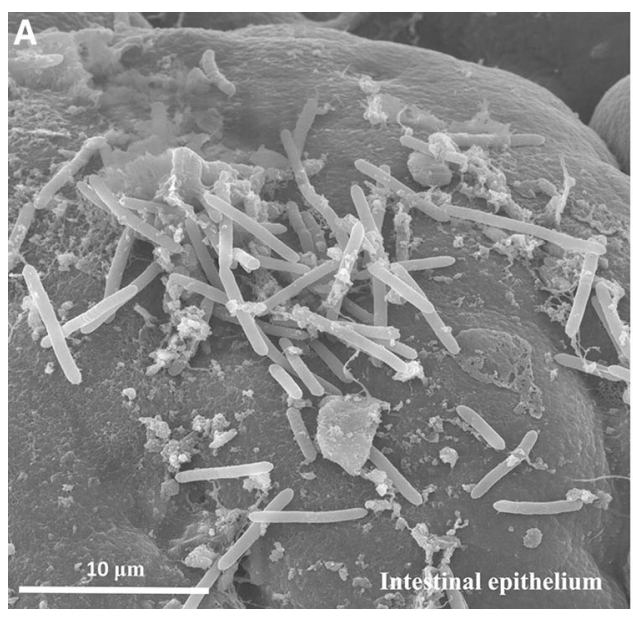

Fig. 1 Morphology of Clostridium butyricum MIYAIRI 588 (CBM588). CBM588 belongs to cluster I, and is a Gram-positive rod-shaped obligate anaerobe. a Germ-free mice were colonized with CBM588 $\left(1 \times 10^{8}\right.$ cells $)$ for 3 weeks. The scanning electron microscopy image shows the proximal colon of CBM588-

PSA can protect against the induction of experimental colitis [90]. Conversely, colonization with a mutant strain that lacks expression of PSA from Bacteroides fragilis does not prevent colitis. Oral treatment of mice with purified PSA protects against TNBS-induced colitis, increases IL10 production, decreases the levels of the proinflammatory cytokines TNF- $\alpha$ and IL-17, and inhibits epithelial cell hyperplasia and neutrophil infiltration into the gut [90]. To provide a mechanistic basis for PSA-mediated protection, it was shown that colonization of germ-free animals with Bacteroides fragilis increased the number of IL-10-producing Foxp3 ${ }^{+} \mathrm{T}_{\text {reg }}$ cells in the gut via TLR2 [11]. Thus, functional Foxp $3^{+} \mathrm{T}_{\text {reg }}$ cells are also produced by PSA during intestinal inflammation through TLR2 signals acting directly on Foxp3 ${ }^{+} \mathrm{T}_{\text {reg }}$ cells to promote IL-10 production [11, 12]. Induction of $\mathrm{T}_{\text {reg }}$ cells is not limited to Bacteroides fragilis, and they are also induced in intestinal clostridia. Atarashi et al. [10] reported that a complex mixture of 46 strains of Clostridium induced transforming growth factor (TGF)- $\beta$ in intestinal epithelial cells that promoted the subsequent accumulation of IL-10-producing induced $\mathrm{T}_{\text {reg }}$ cells, which suppressed colitis in a DSS-induced colitis model. Consistent with these data, germ-free mice were colonized with a mixture of bacterial species, referred to as altered Schaedler flora species, which includes Clostridium species that induce mucosal $\mathrm{T}_{\text {reg }}$ cells specifically in the LP of the colon [64]. To identify $\mathrm{T}_{\mathrm{reg}}{ }^{-}$ cell-inducing bacteria from human stool samples, germfree mice were colonized with the 17 strains of Clostridium belonging to clusters IV, XIVa, and XVIII, derived from a healthy human microbiota [9]. These clostridia induced IL10-producing $\mathrm{T}_{\text {reg }}$ cells that attenuated colitis in mice [9]. Faecalibacterium prausnitzii belongs to Clostridium

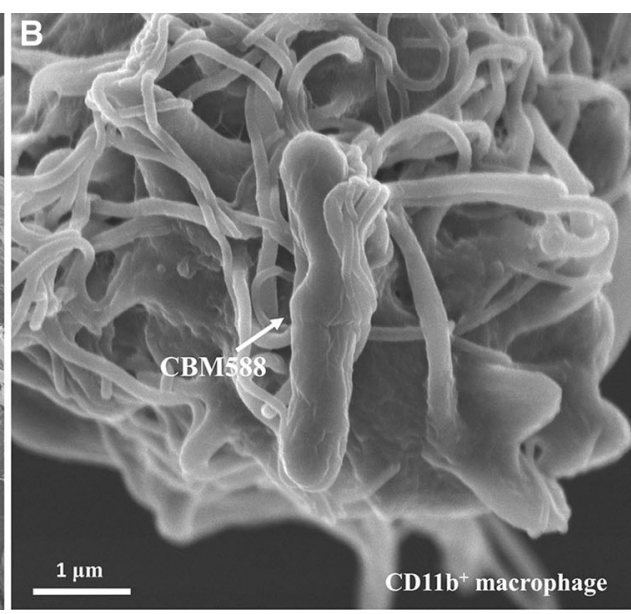

monoassociated mice. $\mathbf{b} \mathrm{CD} 11 \mathrm{~b}^{+}$macrophages from dextran sodium sulfate treated $\mathrm{Rag}^{-\prime-}$ mice were co-cultured with heat-killed CBM588. The scanning electron microscopy image shows phagocytosis of CBM588 by colitic CD11b ${ }^{+}$macrophages.

cluster IV, and its abundance is significantly decreased in Crohn's disease patients as compared with healthy individuals [91]. In addition, oral administration of either live Faecalibacterium prausnitzii or its supernatant markedly reduced the severity of TNBS-induced colitis through the induction of IL-10 [17]. Thus, certain anti-inflammatory commensal microbes might harbor a specific structure to promote IL-10 production by $\mathrm{T}$ cells, regulating gut homeostasis and intestinal inflammation. Recent studies have reported that short-chain fatty acids bind to G-proteincoupled receptor 43 and prevent experimental colitis [92, 93]. Butyrate is produced by commensal microbiota during starch fermentation and promotes extrathymic $T_{\text {reg }}$ cell generation [94]. Histone deacetylase inhibitory activity of butyrate decreases proinflammatory cytokine expression within dendritic cells to promote $\mathrm{T}_{\text {reg }}$ cell induction [94].

All of these findings have demonstrated how the commensal microbiota contributes to modulate colonic $\mathrm{T}_{\text {reg }}$ and $\mathrm{T}_{\mathrm{h}} 17$ cell differentiation and homeostasis, and how the immune system in turn affects the composition of the microbiota.

\section{Clostridium butyricum induces IL-10-producing macrophages}

CBM588 is a Gram-positive rod-shaped obligate anaerobe and spore-forming bacterium [95]. Unlike pathogenic clostridia, such as Clostridium difficile, Clostridium perfringens, and Clostridium botulinum, CBM588 is nonpathogenic and has been used for treatment of human gastrointestinal disease in clinical settings [96, 97]. Several reports have revealed that CBM588 has a potentially 
beneficial anti-inflammatory effect in animals [98], improving nonalcoholic fatty liver disease [99, 100] and preventing Clostridium difficile infection [101, 102]. Although CBM588 has a protective role in some diseases, the precise mechanism by which it exerts its protective anti-inflammatory effect remains unknown. We have reported the anti-inflammatory effect of CBM588 and its mechanism in more detail [13]. Using gnotobiotic techniques, we analyzed whether colonization by a single strain of Clostridium butyricum has an immunomodulatory role in intestinal inflammation (Fig. 1a). Monocolonization of CBM588 exhibited a protective effect in an acute DSSinduced colitis model, accompanied by an increase in IL10 production in the LP mononuclear cells from inflamed intestine. These data suggest that IL-10 production in the intestine contributes to the regulation of colitis. The association between IL-10 and IBD has been demonstrated in several human studies and animal models. IL-10 has been identified as a immunosuppressive cytokine secreted by $T_{h} 2$ cells that inhibits $T_{h} 1$ cell function [103]. Many IL-10expressing cell subsets have been found, such as $T_{h} 1$ cells [103-105], Foxp $3^{+} \mathrm{T}_{\text {reg }}$ cells [106-108], Foxp3 ${ }^{-} \mathrm{T}_{\text {reg }}$ cells [109], B cells [110, 111], macrophages [112-114], dendritic cells [115-117], neutrophils [118], and eosinophils [119]. IL-10-deficient mice are well established as a genetic model for IBD. They developed colitis when they were kept under conventional conditions, but failed to develop colitis when they were raised under germ-free conditions [50, 120]. Furthermore, IL-10-deficient mice developed inflammation restricted to the colon, suggesting that the resident microbiota plays a role in the development of spontaneous colitis [50]. Consistent with this observation, antibiotic therapy can prevent the development of colitis in IL-10 knockout mice [121, 122]. In addition, germ-free IL-10 knockout mice developed colitis after they were colonized with Enterococcus faecalis [123]. A genome-wide association study in humans has shown that a single-nucleotide polymorphism in the $I l 10$ gene is closely associated with IBD [124]. As IL-10 is a key immunoregulatory cytokine, we questioned whether neutralization of IL-10 in DSS-treated, specific-pathogen-free mice with CBM588 could suppress development of colitis. CBM588 treatment cured DSS-induced colitis under specific-pathogen-free conditions; however, the protective effects of CBM588 treatment were completely abrogated by co-administration of anti-IL-10 monoclonal antibody.

$T_{\text {reg }}$ cells play important roles in the establishment and maintenance of immune homeostasis and suppress inflammatory immune responses and autoimmunity [125127]. A recent study demonstrated that cluster IV and XIVa clostridia induce IL-10-producing $\mathrm{T}_{\text {reg }}$ cells in the intestine and prevent experimental colitis $[9,10]$. We have examined whether the anti-inflammatory effect of CBM588 was mediated through $\mathrm{T}_{\mathrm{reg}}$ cells. In inflamed colonic $\mathrm{LP}$ mononuclear cells, IL-10 expression was significantly enhanced in intestinal $\mathrm{CD}_{11 \mathrm{~b}^{+}}$macrophages by CBM588 administration, but not in $\mathrm{CD}^{+}{ }^{+} \mathrm{T}_{\text {reg }}$ cells. To address whether the anti-inflammatory effect of CBM588 was conserved in $\mathrm{T}_{\text {reg }}$ null mice, $\mathrm{CD} 4{ }^{+} \mathrm{CD} 25^{+} \mathrm{T}_{\text {reg-cell-de- }}$ pleted mice were given DSS with or without CBM588 treatment. CBM588 administration suppressed colitis even

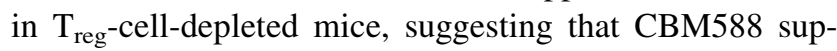
presses intestinal inflammation by a $\mathrm{T}_{\text {reg-cell-independent }}$ anti-inflammatory mechanism. However, CBM588 administration did not fully prevent the development of colitis in the absence of $T_{\text {reg }}$ cells, indicating that $T_{\text {reg }}$ cells also have a partial role in the CBM588-mediated anti-inflammatory effect. Furthermore, CBM588 treatment significantly prevented DSS-induced colitis in RAG-2deficient mice that lack functional $\mathrm{T}$ and $\mathrm{B}$ cells.

TLRs, which recognize specific molecular patterns of microbial components, play an important role in immune and nonimmune functions in the intestine [128, 129]. Macrophages induce IL-10 following stimulation of specific pattern recognition receptors [130-132], and TLR2 signaling is essential for the induction of IL-10 production by macrophages [133]. CBM588 failed to increase the production of IL-10 by intestinal macrophages in the steady state, whereas it directly stimulated intestinal macrophages through the TLR2/MyD88 signaling pathway and induced IL-10 production by macrophages in inflamed conditions (Fig. 1b). Platt et al. [134] identified two subsets of colonic macrophages in mice, whose proportions differed in healthy and inflamed intestine. Under steady-state conditions, most $\mathrm{F} 4 / 80^{+}$macrophages lacked TLR2 expression in response to stimulation. However, during experimental colitis, monocyte-derived chemokine CC receptor (CCR) 2 dependent macrophages expressed TLR2 [134, 135]. Thus, this difference in responsiveness to microbial ligands between resident and inflammatory macrophages might explain the failed induction of macrophage-mediated IL-10 production by CBM588 under physiological conditions. We have indicated that IL-10 is the important factor in the anti-inflammatory effect of CBM588, and that CBM588 induces IL-10 production by intestinal macrophages rather than $\mathrm{T}$ cells. To confirm the direct effect of macrophage-produced IL-10 in preventing colitis following CBM588 treatment, CBM588 was administered to DSS-treated macrophage-specific IL-10 knockout mice. CBM588-fed macrophage-specific IL-10-deficient mice failed to improve DSS-induced colitis in terms of weight loss and histological score, suggesting IL-10-producing macrophages induced by CBM588 are essential for the prevention of colitis. These findings clarify the role of a probiotic strain of Clostridium butyricum, which regulates 
A

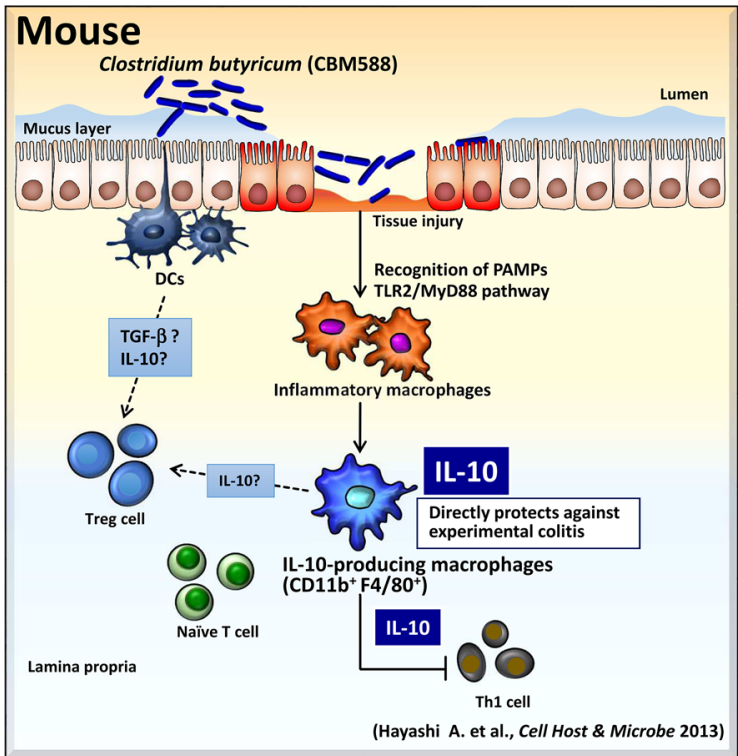

Fig. 2 a Dextran sodoim sulfate treatment of mice allowed bacteria to invade the colon mucus layer and penetrate the epithelial barrier into the lamina propria. In the inflamed condition, Clostridium butyricum MIYAIRI 588 directly stimulated intestinal macrophages through the Toll-like receptor 2 (TLR2)/myeloid differentiation primary response gene $88(M y D 88)$ signaling pathway and induced interleukin (IL)-10 production by macrophages in mice. b CD14 ${ }^{+-}$ $\mathrm{CD}_{3}{ }^{+}$macrophages isolated from human lamina propria stimulated

IL-10 production by intestinal macrophages in inflamed mucosa, and prevents the development of colitis. Control of inflammatory macrophages in IBD is crucial for the therapeutic strategy. Consistent with the data showing that intestinal macrophages in mice do not express TLRs in normal conditions in response to bacterial stimulation, human intestinal macrophages lack or express low levels of innate response receptors, including TLRs and lipopolysaccharide co-receptor CD14 [136-138]. Resident intestinal macrophages also do not produce proinflammatory cytokines, including IL-1, IL-6, IL- 8 , and TNF- $\alpha$, which mediate inflammatory reactions [136]. Our group previously reported that the levels of CD14-expressing macrophages were increased in the intestinal mucosa of patients with IBD [139]. The levels of $\mathrm{CD} 14^{+} \mathrm{CD} 33^{+}$ macrophages expressing chemokine receptors such as CCR1, CCR2, CCR4, CCR9, chemokine CXC receptor (CXCR) 4 and CX3CR1 were increased in IBD patients, especially in those with Crohn's disease [139]. To analyze the response to commensal bacterial stimulation, $\mathrm{CD}_{14}{ }^{+} \mathrm{CD} 33^{+}$and $\mathrm{CD} 14^{-} \mathrm{CD} 33^{+}$cells isolated from $\mathrm{LP}$ were stimulated with Enterococcus faecalis, and inflammatory cytokine production were assessed. $\mathrm{CD} 14^{+} \mathrm{CD} 33^{+}$ cells but not $\mathrm{CD} 4^{-} \mathrm{CD} 33^{+}$cells from Crohn's disease patients induced IL-12/IL-23p40, IL-23, TNF- $\alpha$, and IL-6
B

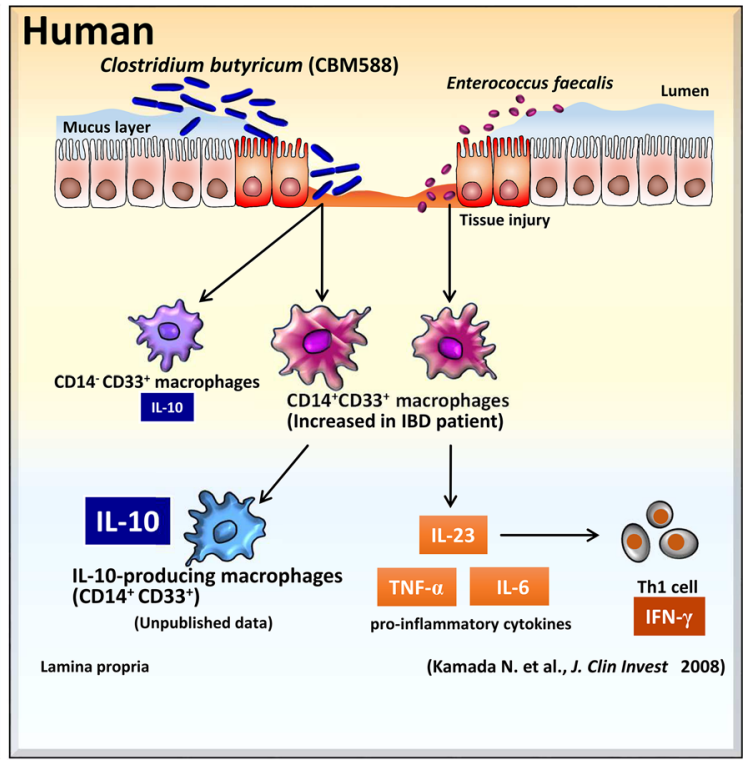

with Enterococcus faecalis induced proinflammatory cytokines, such as IL-12/IL-23p40, IL-23, tumor necrosis factor $\alpha(T N F-\alpha)$, and IL-6. However, Clostridium butyricum MIYAIRI 588 stimulation induced higher levels of IL-10 in $\mathrm{CD} 14^{+} \mathrm{CD} 33^{+}$lamina propria macrophages from human inflammatory bowel disease (IBD) tissue. DCs dendritic cells, IFN interferon, $P A M P s$ pathogen-associated molecular patterns, $T G F$ transforming growth factor, Th1 cell $\mathrm{T}$ helper 1 cell, Treg cell regulatory $\mathrm{T}$ cell

production [139]. TNF- $\alpha$ and IL-23 are major proinflammatory cytokines secreted by macrophages; therefore, these inflammatory macrophages contribute to the pathogenesis of the disease. In addition, LP macrophages stimulated with bacteria induced IFN- $\gamma$ production from $\mathrm{CD}^{+}{ }^{+} \mathrm{T}$ cell via IL-23 $[139,140]$. CBM588 regulates IL10 production by intestinal macrophages in inflamed mucosa in animal experiments; therefore, we tried to establish the involvement of the anti-inflammatory effect of CBM588 in human tissue. $\mathrm{CD}^{+} 4^{+}$monocytes from peripheral blood mononuclear cells or $\mathrm{CD} 14^{+} \mathrm{LP}$ macrophages were stimulated with or without heat-killed CBM588 or Enterococcus faecalis, and production of IL10 in culture supernatants was measured. CBM588 stimulation induced IL-10 production in $\mathrm{CD} 14^{+}$monocytes of human peripheral blood mononuclear cells as compared with Enterococcus faecalis stimulation, but decreased TNF- $\alpha$ production (unpublished data). Moreover, CBM588 stimulation also induced higher levels of IL-10 in $\mathrm{CD}_{14}{ }^{+} \mathrm{CD} 33^{+} \mathrm{LP}$ macrophages from human IBD tissue as compared with Enterococcus faecalis (unpublished data). Although IL-10 therapy for IBD has not been successful, owing to ineffective delivery to the inflammatory site in the LP, bacterial therapy that induces high amounts of IL-10 directly in the intestinal mucosa 
may be a new therapeutic approach for IBD. Therefore, CBM588 may have potential as an immunomodulatory probiotic for both maintenance and induction of remission in IBD, by targeting intestinal macrophages (Fig. 2).

\section{Conclusion}

The gut immune system interacts with the gut microbiota and maintains intestinal homeostasis. Accumulating evidence supports the idea that imbalance in this complicated network between the host and the microbiota is involved in the pathogenesis of gut inflammatory diseases, including IBD. Recently, various studies have explored adjustment of dysbiosis, using probiotics or fecal microbiota transplantation [2, 141-143]. However, it is unclear how these treatments act on the host immune system and commensal bacteria. CBM588 has been long used in clinical settings in Japan. Our recent findings using animal models suggest that CBM588 may induce IL-10-producing immunoregulatory macrophages and have potential as a safer therapeutic option for gut inflammatory diseases. Further clinical evidence of targeting the gut microbiota or combination with conventional therapy will be gathered from clinical and basic research into the microbiota and disease.

Acknowledgments We thank Shinta Mizuno, Hiroki Kiyohara, Mari Arai, Mina Kitazume, Kozue Takeshita, Keiichiro Saigusa, Makoto Naganuma, Katsuyoshi Matsuoka, Toshiro Sato, and Tadakazu Hisamatsu (Keio University) for technical assistance and for valuable discussion. This study was supported in part by Grants-inAid for Scientific Research, Scientific Research on Priority Areas, Exploratory Research and Creative Scientific Research from the Japanese Ministry of Education, Culture, Sports, Science and Technology, the Japanese Ministry of Health, Labour and Welfare, and the Keio University Medical Fund.

Conflict of interest Atsushi Hayashi is an employee of Miyarisan Pharmaceutical. The other authors declare that they have no conflict of interest.

\section{References}

1. Khor B, Gardet A, Xavier RJ. Genetics and pathogenesis of inflammatory bowel disease. Nature. 2011;474(7351):307-17.

2. Sheehan D, Moran C, Shanahan F. The microbiota in inflammatory bowel disease. J Gastroenterol. 2015. doi:10.1007/ s00535-015-1064-1.

3. Human Microbiome Project Consortium. Structure, function and diversity of the healthy human microbiome. Nature. 2012;486(7402):207-14.

4. O'Hara AM, Shanahan F. The gut flora as a forgotten organ. EMBO Rep. 2006;7(7):688-93.

5. Frank DN, St Amand AL, Feldman RA, et al. Molecular-phylogenetic characterization of microbial community imbalances in human inflammatory bowel diseases. Proc Natl Acad Sci U S A. $2007 ; 104(34): 13780-5$.
6. Eckburg PB, Bik EM, Bernstein CN, et al. Diversity of the human intestinal microbial flora. Science. 2005;308(5728): $1635-8$.

7. Garrett WS, Lord GM, Punit S, et al. Communicable ulcerative colitis induced by T-bet deficiency in the innate immune system. Cell. 2007;131(1):33-45.

8. Elinav E, Strowig T, Kau AL, et al. NLRP6 inflammasome regulates colonic microbial ecology and risk for colitis. Cell. 2011;145(5):745-57.

9. Atarashi K, Tanoue T, Oshima K, et al. Treg induction by a rationally selected mixture of clostridia strains from the human microbiota. Nature. 2013;500(7461):232-6.

10. Atarashi K, Tanoue T, Shima T, et al. Induction of colonic regulatory $\mathrm{T}$ cells by indigenous Clostridium species. Science. 2011;331(6015):337-41.

11. Round JL, Mazmanian SK. Inducible Foxp3+ regulatory T-cell development by a commensal bacterium of the intestinal microbiota. Proc Natl Acad Sci U S A. 2010;107(27):12204-9.

12. Round JL, Lee SM, Li J, et al. The Toll-like receptor 2 pathway establishes colonization by a commensal of the human microbiota. Science. 2011;332(6032):974-7.

13. Hayashi A, Sato T, Kamada N, et al. A single strain of Clostridium butyricum induces intestinal IL-10-producing macrophages to suppress acute experimental colitis in mice. Cell Host Microbe. 2013;13(6):711-22.

14. Podolsky DK. Inflammatory bowel disease. $\mathrm{N}$ Engl J Med. 1991;325(13):928-37.

15. Goldsmith JR, Sartor RB. The role of diet on intestinal microbiota metabolism: downstream impacts on host immune function and health, and therapeutic implications. J Gastroenterol. 2014;49(5):785-98.

16. Sokol H, Lay C, Seksik P, et al. Analysis of bacterial bowel communities of IBD patients: what has it revealed? Inflamm Bowel Dis. 2008;14(6):858-67.

17. Sokol H, Pigneur B, Watterlot L, et al. Faecalibacterium prausnitzii is an anti-inflammatory commensal bacterium identified by gut microbiota analysis of Crohn disease patients. Proc Natl Acad Sci U S A. 2008;105(43):16731-6.

18. Feller M, Huwiler K, Stephan R, et al. Mycobacterium avium subspecies paratuberculosis and Crohn's disease: a systematic review and meta-analysis. Lancet Infect Dis. 2007;7(9):607-13.

19. Selby W, Pavli P, Crotty B, et al. Two-year combination antibiotic therapy with clarithromycin, rifabutin, and clofazimine for Crohn's disease. Gastroenterology. 2007;132(7):2313-9.

20. Chen W, Li D, Paulus B, et al. Detection of Listeria monocytogenes by polymerase chain reaction in intestinal mucosal biopsies from patients with inflammatory bowel disease and controls. J Gastroenterol Hepatol. 2000;15(10):1145-50.

21. Ontanilla Clavijo G, Trigo Salado C, Leo Carnerero E, et al. Listeria monocytogenes y su relacion con terapia no biologica en la enfermedad inflamatoria intestinal. Gastroenterol Hepatol. 2014. doi:10.1016/j.gastrohep.2014.07.001.

22. Rolhion N, Darfeuille-Michaud A. Adherent-invasive Escherichia coli in inflammatory bowel disease. Inflamm Bowel Dis. 2007;13(10):1277-83.

23. Ohkusa T, Sato N, Ogihara T, et al. Fusobacterium varium localized in the colonic mucosa of patients with ulcerative colitis stimulates species-specific antibody. J Gastroenterol Hepatol. 2002;17(8):849-53.

24. Okayasu I, Hatakeyama S, Yamada M, et al. A novel method in the induction of reliable experimental acute and chronic ulcerative colitis in mice. Gastroenterology. 1990;98(3):694-702.

25. Dieleman LA, Ridwan BU, Tennyson GS, et al. Dextran sulfate sodium-induced colitis occurs in severe combined immunodeficient mice. Gastroenterology. 1994;107(6):1643-52. 
26. Axelsson LG, Landstrom E, Goldschmidt TJ, et al. Dextran sulfate sodium (DSS) induced experimental colitis in immunodeficient mice: effects in $\mathrm{CD} 4^{+}$-cell depleted, athymic and NKcell depleted SCID mice. Inflamm Res. 1996;45(4):181-91.

27. Krieglstein CF, Cerwinka WH, Sprague AG, et al. Collagenbinding integrin $\alpha_{1} \beta_{1}$ regulates intestinal inflammation in experimental colitis. J Clin Investig. 2002;110(12):1773-82.

28. Kim TW, Seo JN, Suh YH, et al. Involvement of lymphocytes in dextran sulfate sodium-induced experimental colitis. World $\mathbf{J}$ Gastroenterol. 2006;12(2):302-5.

29. Johansson ME, Gustafsson JK, Holmen-Larsson J, et al. Bacteria penetrate the normally impenetrable inner colon mucus layer in both murine colitis models and patients with ulcerative colitis. Gut. 2014;63(2):281-91.

30. Johansson ME, Gustafsson JK, Sjoberg KE, et al. Bacteria penetrate the inner mucus layer before inflammation in the dextran sulfate colitis model. PLoS One. 2010;5(8):e12238.

31. Alex P, Zachos NC, Nguyen T, et al. Distinct cytokine patterns identified from multiplex profiles of murine DSS and TNBSinduced colitis. Inflamm Bowel Dis. 2009;15(3):341-52.

32. Dieleman LA, Palmen MJ, Akol H, et al. Chronic experimental colitis induced by dextran sulphate sodium (DSS) is characterized by Th1 and Th2 cytokines. Clin Exp Immunol. 1998; 114(3):385-91.

33. Fujino S, Andoh A, Bamba S, et al. Increased expression of interleukin 17 in inflammatory bowel disease. Gut. 2003;52(1): $65-70$.

34. Ogawa A, Andoh A, Araki Y, et al. Neutralization of interleukin-17 aggravates dextran sulfate sodium-induced colitis in mice. Clin Immunol. 2004;110(1):55-62.

35. Rakoff-Nahoum S, Paglino J, Eslami-Varzaneh $F$, et al. Recognition of commensal microflora by Toll-like receptors is required for intestinal homeostasis. Cell. 2004;118(2):229-41.

36. Araki A, Kanai T, Ishikura T, et al. MyD88-deficient mice develop severe intestinal inflammation in dextran sodium sulfate colitis. J Gastroenterol. 2005;40(1):16-23.

37. Gupta RB, Harpaz N, Itzkowitz S, et al. Histologic inflammation is a risk factor for progression to colorectal neoplasia in ulcerative colitis: a cohort study. Gastroenterology. 2007;133(4): 1099-105; quiz 1340-1.

38. Tanaka T, Kohno H, Suzuki R, et al. A novel inflammationrelated mouse colon carcinogenesis model induced by azoxymethane and dextran sodium sulfate. Cancer Sci. 2003;94(11): 965-73.

39. Krelin $\mathrm{Y}$, Voronov E, Dotan $\mathrm{S}$, et al. Interleukin-1 $\beta$-driven inflammation promotes the development and invasiveness of chemical carcinogen-induced tumors. Cancer Res. 2007;67(3): 1062-71.

40. Tamura K, Fukuda Y, Sashio H, et al. IL18 polymorphism is associated with an increased risk of Crohn's disease. J Gastroenterol. 2002;37(Suppl 14):111-6.

41. Salcedo R, Worschech A, Cardone M, et al. MyD88-mediated signaling prevents development of adenocarcinomas of the colon: role of interleukin 18. J Exp Med. 2010;207(8):1625-36.

42. Wang Y, Wang K, Han GC, et al. Neutrophil infiltration favors colitis-associated tumorigenesis by activating the interleukin-1 (IL-1)/IL-6 axis. Mucosal Immunol. 2014;7(5):1106-15.

43. Boirivant M, Fuss IJ, Chu A, et al. Oxazolone colitis: a murine model of T helper cell type 2 colitis treatable with antibodies to interleukin 4. J Exp Med. 1998;188(10):1929-39.

44. Heller F, Fuss IJ, Nieuwenhuis EE, et al. Oxazolone colitis, a Th2 colitis model resembling ulcerative colitis, is mediated by IL-13-producing NK-T cells. Immunity. 2002;17(5):629-38.

45. Neurath MF, Fuss I, Kelsall BL, et al. Antibodies to interleukin 12 abrogate established experimental colitis in mice. J Exp Med. 1995;182(5):1281-90.
46. Oppmann B, Lesley R, Blom B, et al. Novel p19 protein engages IL-12p40 to form a cytokine, IL-23, with biological activities similar as well as distinct from IL-12. Immunity. 2000;13(5): 715-25.

47. Yen D, Cheung J, Scheerens H, et al. IL-23 is essential for T cell-mediated colitis and promotes inflammation via IL-17 and IL-6. J Clin Investig. 2006;116(5):1310-6.

48. Becker C, Dornhoff H, Neufert C, et al. Cutting edge: IL-23 cross-regulates IL-12 production in $\mathrm{T}$ cell-dependent experimental colitis. J Immunol. 2006;177(5):2760-4.

49. Kuhn R, Lohler J, Rennick D, et al. Interleukin-10-deficient mice develop chronic enterocolitis. Cell. 1993;75(2):263-74.

50. Sellon RK, Tonkonogy S, Schultz M, et al. Resident enteric bacteria are necessary for development of spontaneous colitis and immune system activation in interleukin-10-deficient mice. Infect Immun. 1998;66(11):5224-31.

51. Powrie F, Leach MW, Mauze S, et al. Phenotypically distinct subsets of $\mathrm{CD} 4+\mathrm{T}$ cells induce or protect from chronic intestinal inflammation in C. B-17 scid mice. Int Immunol. 1993;5(11):1461-71.

52. Totsuka T, Kanai T, Nemoto Y, et al. IL-7 Is essential for the development and the persistence of chronic colitis. J Immunol. 2007;178(8):4737-48.

53. Kanai T, Kawamura T, Dohi T, et al. TH1/TH2-mediated colitis induced by adoptive transfer of $\mathrm{CD} 4{ }^{+} \mathrm{CD} 45 \mathrm{RB}^{\text {high }} \mathrm{T}$ lymphocytes into nude mice. Inflamm Bowel Dis. 2006;12(2):89-99.

54. Davidson NJ, Hudak SA, Lesley RE, et al. IL-12, but not IFN- $\gamma$, plays a major role in sustaining the chronic phase of colitis in IL-10-deficient mice. J Immunol. 1998;161(6):3143-9.

55. Asseman C, Mauze S, Leach MW, et al. An essential role for interleukin 10 in the function of regulatory $\mathrm{T}$ cells that inhibit intestinal inflammation. J Exp Med. 1999;190(7):995-1004.

56. Neurath MF, Weigmann B, Finotto S, et al. The transcription factor T-bet regulates mucosal $\mathrm{T}$ cell activation in experimental colitis and Crohn's disease. J Exp Med. 2002;195(9):1129-43.

57. Simpson SJ, Shah S, Comiskey $M$, et al. T cell-mediated pathology in two models of experimental colitis depends predominantly on the interleukin 12/Signal transducer and activator of transcription (Stat)-4 pathway, but is not conditional on interferon gamma expression by T cells. J Exp Med. 1998;187(8): 1225-34.

58. O'Connor W Jr, Kamanaka M, Booth CJ, et al. A protective function for interleukin 17A in $\mathrm{T}$ cell-mediated intestinal inflammation. Nat Immunol. 2009;10(6):603-9.

59. Leppkes M, Becker C, Ivanov II, et al. ROR $\gamma$-expressing Th17 cells induce murine chronic intestinal inflammation via redundant effects of IL-17A and IL-17F. Gastroenterology. 2009;136(1):257-67.

60. Durant L, Watford WT, Ramos HL, Laurence A, Vahedi G, Wei L, et al. Diverse targets of the transcription factor STAT3 contribute to $\mathrm{T}$ cell pathogenicity and homeostasis. Immunity. 2010;32(5):605-15.

61. Mikami Y, Kanai T, Sujino T, et al. Competition between colitogenic Th1 and Th17 cells contributes to the amelioration of colitis. Eur J Immunol. 2010;40(9):2409-22.

62. Sujino T, Kanai T, Ono Y, et al. Regulatory $\mathrm{T}$ cells suppress development of colitis, blocking differentiation of T-helper 17 into alternative T-helper 1 cells. Gastroenterology. 2011;141(3): 1014-23.

63. Saigusa K, Hisamatsu T, Handa T, et al. Classical Th1 cells obtain colitogenicity by co-existence of RORgammat-expressing $\mathrm{T}$ cells in experimental colitis. Inflamm Bowel Dis. 2014;20(10):1820-7.

64. Geuking MB, Cahenzli J, Lawson MA, et al. Intestinal bacterial colonization induces mutualistic regulatory $\mathrm{T}$ cell responses. Immunity. 2011;34(5):794-806. 
65. Tremaroli V, Backhed F. Functional interactions between the gut microbiota and host metabolism. Nature. 2012;489(7415): 242-9.

66. Sczesnak A, Segata N, Qin X, et al. The genome of Th17 cellinducing segmented filamentous bacteria reveals extensive auxotrophy and adaptations to the intestinal environment. Cell Host Microbe. 2011;10(3):260-72.

67. Ivanov II, Frutos Rde L, Manel N, et al. Specific microbiota direct the differentiation of IL-17-producing T-helper cells in the mucosa of the small intestine. Cell Host Microbe. 2008;4(4):337-49.

68. Gaboriau-Routhiau V, Rakotobe S, Lecuyer E, et al. The key role of segmented filamentous bacteria in the coordinated maturation of gut helper $\mathrm{T}$ cell responses. Immunity. 2009;31(4):677-89.

69. Ivanov II, Atarashi K, Manel N, et al. Induction of intestinal Th17 cells by segmented filamentous bacteria. Cell. 2009;139(3):485-98.

70. Yang Y, Torchinsky MB, Gobert M, et al. Focused specificity of intestinal TH17 cells towards commensal bacterial antigens. Nature. 2014;510(7503):152-6.

71. Goto Y, Panea C, Nakato G, et al. Segmented filamentous bacteria antigens presented by intestinal dendritic cells drive mucosal Th17 cell differentiation. Immunity. 2014;40(4): 594-607.

72. Cella M, Fuchs A, Vermi W, et al. A human natural killer cell subset provides an innate source of IL-22 for mucosal immunity. Nature. 2009;457(7230):722-5.

73. Eberl G, Di Santo JP, Vivier E. The brave new world of innate lymphoid cells. Nat Immunol. 2015;16(1):1-5.

74. Diefenbach A. Profiling the diversity of innate lymphoid cells. Nat Immunol. 2015;16(3):222-4.

75. Spits H, Artis D, Colonna M, et al. Innate lymphoid cells-a proposal for uniform nomenclature. Nat Rev Immunol. 2013;13(2):145-9.

76. Mizuno S, Mikami Y, Kamada N, et al. Cross-talk between ROR $\gamma \mathrm{t}+$ innate lymphoid cells and intestinal macrophages induces mucosal IL-22 production in Crohn's disease. Inflamm Bowel Dis. 2014;20(8):1426-34.

77. Takayama $\mathrm{T}$, Kamada $\mathrm{N}$, Chinen $\mathrm{H}$, et al. Imbalance of $\mathrm{NKp} 44^{+} \mathrm{NKp} 46^{-}$and $\mathrm{NKp} 44^{-} \mathrm{NKp} 46^{+}$natural killer cells in the intestinal mucosa of patients with Crohn's disease. Gastroenterology. 2010;139(3):882-92.e3.

78. Wolk K, Kunz S, Witte E. IL-22 increases the innate immunity of tissues. Immunity. 2004;21(2):241-54.

79. Mizoguchi A. Healing of intestinal inflammation by IL-22. Inflamm Bowel Dis. 2012;18(9):1777-84.

80. Zenewicz LA, Flavell RA. Recent advances in IL-22 biology. Int Immunol. 2011;23(3):159-63.

81. Kimura K, Kanai T, Hayashi A, et al. Dysregulated balance of retinoid-related orphan receptor $\gamma \mathrm{t}$-dependent innate lymphoid cells is involved in the pathogenesis of chronic DSSinduced colitis. Biochem Biophys Res Commun. 2012;427(4): 694-700.

82. Basu R, O'Quinn DB, Silberger DJ, et al. Th22 cells are an important source of IL-22 for host protection against enteropathogenic bacteria. Immunity. 2012;37(6):1061-75.

83. Sonnenberg GF, Monticelli LA, Elloso MM, et al. CD4 ${ }^{+}$lymphoid tissue-inducer cells promote innate immunity in the gut. Immunity. 2011;34(1):122-34.

84. Zheng Y, Valdez PA, Danilenko DM, et al. Interleukin-22 mediates early host defense against attaching and effacing bacterial pathogens. Nat Med. 2008;14(3):282-9.

85. Sonnenberg GF, Monticelli LA, Alenghat T, et al. Innate lymphoid cells promote anatomical containment of lymphoid-resident commensal bacteria. Science. 2012;336(6086):1321-5.
86. Suzuki K, Meek B, Doi Y. Aberrant expansion of segmented filamentous bacteria in IgA-deficient gut. Proc Natl Acad Sci U S A. 2004;101(7):1981-6.

87. Peterson DA, McNulty NP, Guruge JL, et al. IgA response to symbiotic bacteria as a mediator of gut homeostasis. Cell Host Microbe. 2007;2(5):328-39.

88. Kawamoto S, Maruya M, Kato LM, et al. Foxp $3^{+} \mathrm{T}$ cells regulate immunoglobulin a selection and facilitate diversification of bacterial species responsible for immune homeostasis. Immunity. 2014;41(1):152-65.

89. Mazmanian SK, Liu CH, Tzianabos AO, et al. An immunomodulatory molecule of symbiotic bacteria directs maturation of the host immune system. Cell. 2005;122(1): 107-18.

90. Mazmanian SK, Round JL, Kasper DL. A microbial symbiosis factor prevents intestinal inflammatory disease. Nature. 2008;453(7195):620-5.

91. Fujimoto T, Imaeda H, Takahashi K, et al. Decreased abundance of Faecalibacterium prausnitzii in the gut microbiota of Crohn's disease. J Gastroenterol Hepatol. 2013;28(4):613-9.

92. Maslowski KM, Vieira AT, Ng A, et al. Regulation of inflammatory responses by gut microbiota and chemoattractant receptor GPR43. Nature. 2009;461(7268):1282-6.

93. Furusawa Y, Obata Y, Fukuda S, et al. Commensal microbederived butyrate induces the differentiation of colonic regulatory T cells. Nature. 2013;504(7480):446-50.

94. Arpaia N, Campbell C, Fan X, et al. Metabolites produced by commensal bacteria promote peripheral regulatory T-cell generation. Nature. 2013;504(7480):451-5.

95. Sato R, Tanaka M. Intestinal distribution and intraluminal localization of orally administered Clostridium butyricum in rats. Microbiol Immunol. 1997;41(9):665-71.

96. Seki H, Shiohara M, Matsumura T, et al. Prevention of antibiotic-associated diarrhea in children by Clostridium butyricum MIYAIRI. Pediatr Int. 2003;45(1):86-90.

97. Shimbo I, Yamaguchi T, Odaka T, et al. Effect of Clostridium butyricum on fecal flora in Helicobacter pylori eradication therapy. World J Gastroenterol. 2005;11(47):7520-4.

98. Okamoto T, Sasaki M, Tsujikawa T, et al. Preventive efficacy of butyrate enemas and oral administration of Clostridium butyricum M588 in dextran sodium sulfate-induced colitis in rats. J Gastroenterol. 2000;35(5):341-6.

99. Endo H, Niioka M, Kobayashi N, et al. Butyrate-producing probiotics reduce nonalcoholic fatty liver disease progression in rats: new insight into the probiotics for the gut-liver axis. PLoS One. 2013;8(5):e63388.

100. Seo M, Inoue I, Tanaka M, et al. Clostridium butyricum MIYAIRI 588 improves high-fat diet-induced non-alcoholic fatty liver disease in rats. Dig Dis Sci. 2013;58(12):3534-44.

101. Takahashi M, Taguchi H, Yamaguchi H, et al. The effect of probiotic treatment with Clostridium butyricum on enterohemorrhagic Escherichia coli $\mathrm{O} 157: \mathrm{H} 7$ infection in mice. FEMS Immunol Med Microbiol. 2004;41(3):219-26.

102. Woo TD, Oka K, Takahashi M, et al. Inhibition of the cytotoxic effect of Clostridium difficile in vitro by Clostridium butyricum MIYAIRI 588 strain. J Med Microbiol. 2011;60(Pt 11):1617-25.

103. Fiorentino DF, Bond MW, Mosmann TR. Two types of mouse T helper cell. IV. Th2 clones secrete a factor that inhibits cytokine production by Th1 clones. J Exp Med. 1989;170(6):2081-95.

104. Moore KW, Vieira P, Fiorentino DF, et al. Homology of cytokine synthesis inhibitory factor (IL-10) to the Epstein-Barr virus gene BCRFI. Science. 1990;248(4960):1230-4.

105. Jankovic D, Kullberg MC, Feng CG, et al. Conventional T-bet ${ }^{+}$Foxp $3^{-}$Th1 cells are the major source of host-protective regulatory IL-10 during intracellular protozoan infection. J Exp Med. 2007;204(2):273-83. 
106. Rubtsov YP, Rasmussen JP, Chi EY, et al. Regulatory T cellderived interleukin-10 limits inflammation at environmental interfaces. Immunity. 2008;28(4):546-58.

107. Suffia IJ, Reckling SK, Piccirillo CA, et al. Infected site-restricted Foxp $3^{+}$natural regulatory $\mathrm{T}$ cells are specific for microbial antigens. J Exp Med. 2006;203(3):777-88.

108. Zhang X, Koldzic DN, Izikson L, et al. IL-10 is involved in the suppression of experimental autoimmune encephalomyelitis by $\mathrm{CD} 25^{+} \mathrm{CD} 4^{+}$regulatory $\mathrm{T}$ cells. Int Immunol. 2004;16(2): $249-56$.

109. Groux H, O'Garra A, Bigler M, Rouleau M, Antonenko S, de Vries JE, et al. A CD4 ${ }^{+}$T-cell subset inhibits antigen-specific T-cell responses and prevents colitis. Nature. 1997;389(6652): 737-42.

110. O'Garra A, Chang R, Go N, et al. Ly-1 B (B-1) cells are the main source of B cell-derived interleukin 10. Eur J Immunol. 1992;22(3):711-7.

111. Fillatreau S, Sweenie CH, McGeachy MJ, et al. B cells regulate autoimmunity by provision of IL-10. Nat Immunol. 2002;3(10): 944-50.

112. Denning TL, Wang YC, Patel SR, et al. Lamina propria macrophages and dendritic cells differentially induce regulatory and interleukin 17-producing $\mathrm{T}$ cell responses. Nat Immunol. 2007;8(10):1086-94.

113. Rivollier A, He J, Kole A, et al. Inflammation switches the differentiation program of Ly6Chi monocytes from antiinflammatory macrophages to inflammatory dendritic cells in the colon. J Exp Med. 2012;209(1):139-55.

114. Katakura T, Miyazaki M, Kobayashi M, et al. CCL17 and IL-10 as effectors that enable alternatively activated macrophages to inhibit the generation of classically activated macrophages. J Immunol. 2004;172(3):1407-13.

115. Corinti S, Albanesi C, la Sala A, et al. Regulatory activity of autocrine IL-10 on dendritic cell functions. J Immunol. 2001;166(7):4312-8.

116. McGuirk P, McCann C, Mills KH. Pathogen-specific T regulatory 1 cells induced in the respiratory tract by a bacterial molecule that stimulates interleukin 10 production by dendritic cells: a novel strategy for evasion of protective T helper type 1 responses by Bordetella pertussis. J Exp Med. 2002;195(2): 221-31.

117. Chirdo FG, Millington OR, Beacock-Sharp H, et al. Immunomodulatory dendritic cells in intestinal lamina propria. Eur J Immunol. 2005;35(6):1831-40.

118. Romani L, Mencacci A, Cenci E, et al. Neutrophil production of IL-12 and IL-10 in candidiasis and efficacy of IL-12 therapy in neutropenic mice. J Immunol. 1997;158(11):5349-56.

119. Kayaba H, Dombrowicz D, Woerly G, et al. Human eosinophils and human high affinity IgE receptor transgenic mouse eosinophils express low levels of high affinity IgE receptor, but release IL-10 upon receptor activation. J Immunol. 2001;167(2): 995-1003.

120. Kim SC, Tonkonogy SL, Albright CA, et al. Variable phenotypes of enterocolitis in interleukin 10-deficient mice monoassociated with two different commensal bacteria. Gastroenterology. 2005;128(4):891-906.

121. Hoentjen F, Harmsen HJ, Braat $\mathrm{H}$, et al. Antibiotics with a selective aerobic or anaerobic spectrum have different therapeutic activities in various regions of the colon in interleukin 10 gene deficient mice. Gut. 2003;52(12):1721-7.

122. Madsen KL, Doyle JS, Tavernini MM, et al. Antibiotic therapy attenuates colitis in interleukin 10 gene-deficient mice. Gastroenterology. 2000;118(6):1094-105.

123. Balish E, Warner T. Enterococcus faecalis induces inflammatory bowel disease in interleukin-10 knockout mice. Am J Pathol. 2002;160(6):2253-7.
124. Franke A, Balschun T, Karlsen TH, et al. Sequence variants in IL10, ARPC2 and multiple other loci contribute to ulcerative colitis susceptibility. Nat Genet. 2008;40(11):1319-23 .

125. Chen Z, Barbi J, Bu S, et al. The ubiquitin ligase Stub1 negatively modulates regulatory $\mathrm{T}$ cell suppressive activity by promoting degradation of the transcription factor Foxp3. Immunity. 2013;39(2):272-85.

126. Liston A, Gray DH. Homeostatic control of regulatory $\mathrm{T}$ cell diversity. Nat Rev Immunol. 2014;14(3):154-65.

127. Sakaguchi S, Yamaguchi T, Nomura T, et al. Regulatory T cells and immune tolerance. Cell. 2008;133(5):775-87.

128. Akira S, Takeda K, Kaisho T. Toll-like receptors: critical proteins linking innate and acquired immunity. Nat Immunol. 2001;2(8):675-80.

129. Medzhitov R. Toll-like receptors and innate immunity. Nat Rev Immunol. 2001;1(2):135-45.

130. Boonstra A, Rajsbaum R, Holman M, et al. Macrophages and myeloid dendritic cells, but not plasmacytoid dendritic cells, produce IL-10 in response to MyD88- and TRIF-dependent TLR signals, and TLR-independent signals. J Immunol. 2006;177(11): 7551-8.

131. de Waal Malefyt R, Abrams J, Bennett B, et al. Interleukin 10(IL-10) inhibits cytokine synthesis by human monocytes: an autoregulatory role of IL-10 produced by monocytes. J Exp Med. 1991;174(5):1209-20.

132. Siewe L, Bollati-Fogolin M, Wickenhauser C, et al. Interleukin10 derived from macrophages and/or neutrophils regulates the inflammatory response to LPS but not the response to $\mathrm{CpG}$ DNA. Eur J Immunol. 2006;36(12):3248-55.

133. Dillon S, Agrawal A, Van Dyke T, et al. A Toll-like receptor 2 ligand stimulates Th2 responses in vivo, via induction of extracellular signal-regulated kinase mitogen-activated protein kinase and c-Fos in dendritic cells. J Immunol. 2004;172(8):4733-43.

134. Platt AM, Bain CC, Bordon Y, et al. An independent subset of TLR expressing CCR2-dependent macrophages promotes colonic inflammation. J Immunol. 2010;184(12):6843-54.

135. Mowat AM, Bain CC. Mucosal macrophages in intestinal homeostasis and inflammation. J Innate Immun. 2011;3(6):550-64.

136. Smythies LE, Sellers M, Clements RH, et al. Human intestinal macrophages display profound inflammatory anergy despite avid phagocytic and bacteriocidal activity. J Clin Investig. 2005;115(1):66-75.

137. Grimm MC, Pavli P, Van de Pol E, et al. Evidence for a CD14+ population of monocytes in inflammatory bowel disease mucosa-implications for pathogenesis. Clin Exp Immunol. 1995;100(2):291-7.

138. Smith PD, Smythies LE, Mosteller-Barnum M, et al. Intestinal macrophages lack CD14 and CD89 and consequently are downregulated for LPS- and IgA-mediated activities. J Immunol. 2001;167(5):2651-6.

139. Kamada N, Hisamatsu T, Okamoto S, et al. Unique CD14 ${ }^{+}$ intestinal macrophages contribute to the pathogenesis of Crohn disease via IL-23/IFN- $\gamma$ axis. J Clin Investig. 2008;118(6): 2269-80.

140. Kobayashi T, Okamoto S, Hisamatsu T, et al. IL23 differentially regulates the Th1/Th17 balance in ulcerative colitis and Crohn's disease. Gut. 2008;57(12):1682-9.

141. Matsuoka K, Mizuno S, Hayashi A, et al. Fecal microbiota transplantation for gastrointestinal diseases. Keio $\mathrm{J}$ Med. 2014;63(4):69-74.

142. Sartor RB. Therapeutic manipulation of the enteric microflora in inflammatory bowel diseases: antibiotics, probiotics, and prebiotics. Gastroenterology. 2004;126(6):1620-33.

143. van Nood E, Vrieze A, Nieuwdorp M, et al. Duodenal infusion of donor feces for recurrent Clostridium difficile. N Engl J Med. 2013;368(5):407-15. 